\title{
37. Carbon capture from ambient air: a brake on climate change?
}

\section{Claude Henry}

Within the next ten years, it could prove a perilous disaster to go on increasing the stock of greenhouse gases (GHGs) in the atmosphere. Humankind, however, has not yet curbed increasing volumes of emissions, and doesn't seem determined to do so. How to avoid being squeezed? The only way, which doesn't itself tinker with essential climate mechanisms - as geoengineering projects might do (Barrett, 2012) - is to capture $\mathrm{CO}_{2}$ from the atmosphere, and then dispose of it in various available ways. Capturing $\mathrm{CO}_{2}$ from air and storing it - direct air capture and storage, or DACS - would be an essential complement to avoiding doom on the planet; a complement, definitely not a substitute for reducing the emissions. Driving DACS costs down is thus worth research and development efforts on par with the Apollo Program, as was already laid down 20 years ago in a visionary paper (Lackner et al., 1999). This is all the more justified as, climate change being a public bad, DACS is a public good, ${ }^{1}$ for the provision of which you cannot rely on market mechanisms for raising adequate financial resources, even if you can rely on them to organize some form of competition, via reverse auctions, between providers. ${ }^{2}$

It is often argued that more broadly switching to a sustainable global development trajectory requires an "Apollo Program" of sorts. As long as sustainable development is considered in its globality, Richard Nelson, who along with Kenneth Arrow pioneered the economics of innovation, strongly disagrees: development stems from a broad diversity of decentralized endeavors. Nelson (with Sarewitz), however, also argues that there is one domain of R\&D that calls for an Apollo Program, and that is $\mathrm{CO}_{2}$ capture and storage (Sarewitz and Nelson, 2008).

Nature itself captures $\mathrm{CO}_{2}$ from ambient air. Silicates of calcium or of magnesium are significantly more reactive with ambient $\mathrm{CO}_{2}$ than are other minerals, the reaction forming stable solid carbonates; hence, the name mineral carbonation. They are found at higher densities in several kinds of rocks, particularly basalt and peridotite (Krevor et al., 2009). Natural weathering of such rocks fosters mineral carbonation. Peridotite is particularly productive; unfortunately, while abundant deep underground, it is relatively rare on or near 
the surface of the Earth, with a remarkably high presence in the Sultanate of Oman, which contains about 30 percent of the area where peridotite is apparent on Earth. According to geologists Peter Kelemen and Jürg Matter, who have extensively investigated the area: "In situ, carbonation of peridotite could consume $>1$ billion tons of $\mathrm{CO}_{2}$ per year in Oman alone, affording a low-cost, safe, and permanent method to capture and store atmospheric $\mathrm{CO}_{2}$ " (Kelemen and Matter, 2008, p. 17295). This presupposes fracturing the rock to increase the contact area between air and rock.

As reachable perdotite is relatively rare, carbonation of basalt is the practical alternative, either with $\mathrm{CO}_{2}$ in ambient air, or $\mathrm{CO}_{2}$ dissolved in sea water, as basalt is relatively abundant near land surface and on sea floor. Promising preliminary results have been obtained in Iceland. A project supported by the EU (CarbFix project) and started in 2012 near Reykjavik, has indeed shown the capacity and efficiency of basalt to turn $\mathrm{CO}_{2}$ into veins of stable solid calcite and magnesite. $\mathrm{CO}_{2}$ obtained from a nearby geothermal plant is dissolved in water and then pumped into sea floor basalt. The nice surprise has been the speed of the process: 95 percent of the $\mathrm{CO}_{2}$ injected solidified within two years, whereas a decade was expected. An assessment of the results has been published in Science (Matter et al., 2016).

This project is an experience in $\mathrm{CO}_{2}$ storage, not in capture. A second CarbFix project in Iceland. CarbFix2, deals with both aspects of the problem. It is realized by the Swiss company Climeworks, initially established in 2009 by Christoph Gebald and Jan Wurzbacher as a Swiss Federal Institute of Technology in Zurich (ETHZ) spin-off. Climeworks develops, builds and operates direct air capture (DAC) plants that capture $\mathrm{CO}_{2}$ from air. Climeworks plants consist of modular " $\mathrm{CO}_{2}$ collectors". One key element of Climeworks' technology is a filter material, which selectively captures $\mathrm{CO}_{2}$. In a first step, air is drawn into the $\mathrm{CO}_{2}$ collector using a fan. $\mathrm{CO}_{2}$ is then captured on the surface of the filter material ("adsorption"). In a second step, when the filter material is fully saturated, the $\mathrm{CO}_{2}$ collector is closed and the temperature increased to between $80^{\circ} \mathrm{C}$ and $100^{\circ} \mathrm{C}$. The $\mathrm{CO}_{2}$ thereby releases ("desorption") at a purity of over 99 percent and can be collected. The $\mathrm{CO}_{2}$ that has been collected in this way is pumped into underground basalt, with results similar to those obtained in the first CarbFix project. ${ }^{3}$

Climeworks already has 14 plants in operation across Europe. Most of them do not pump the $\mathrm{CO}_{2}$ underground for mineralization. Instead, the $\mathrm{CO}_{2}$ is re-used for various applications, such as for the fertilization of greenhouses, for the carbonation of drinks or for the production of renewable synthetic fuels, as is the case in the plant Climeworks has built in Italy. The idea has been promoted for some years by George Olah, a Nobel laureate who is a legend 
in the chemistry of hydrocarbons. Olah, Surya Prakash and Goeppert (Loker Hydrocarbon Research Institute, University of Southern California):

have proposed and developed a feasible anthropogenic chemical recycling of carbon dioxide [that can] be converted by feasible chemical transformations into liquid fuels such as methanol, dimethyl ether... The required energy for the synthetic carbon cycle can come from any alternative energy source such as solar, wind, geothermal, and even hopefully safe nuclear energy. (Olah, Surya Prakash and Goeppert, 2011, p. 12881)

This way of storing $\mathrm{CO}_{2}$ would not reduce the amount already present in the atmosphere, but it would at least close the open carbon cycle associated with the burning of fuels made from fossil oil.

Anders Eldrup, then CEO of the Danish power utility DONG Energy (now called Oersted), had not heard of Olah et al. However, he came to concur with them. During the winter 2009-10, the Danish wind farms produced such an excess of electricity, which by all means had to be evacuated through the interconnectors to Norway and Sweden, that the price became negative. With the multiplication of offshore wind farms in Danish and British waters, it is anticipated that imbalances between production and consumption of electricity might result in negative prices for about 1000 hours/year. Anders Eldrup came to the view that, rather than excess electricity generating losses, it should be used to produce hydrogen. Similar conditions will prevail in the USA, in places across Texas and Midwestern states, where the development of wind farms is massive. In many other places, solar energy would do the job. Then, with $\mathrm{CO}_{2}$ and cheap hydrogen at hand, it will be economical to produce the synthetic fuels envisaged by Olah et al., not only providing substitutes for fossil fuels but also, these fuels being a safe means of storage, contributing to mitigating the intermittency and volatility of renewables. Moreover, they could easily be fed into existing energy infrastructure, far more energy being carried economically in this way than along power lines.

What about DACS costs? High costs make $\mathrm{CO}_{2}$ capture from ambient air impracticable, I remember Robert Sokolow, the eminent Princeton physicist and energy expert, saying five or six years ago. More recently, he has co-signed a paper (Creutzig et al., 2019) that sounds far less pessimistic. There are good reasons for that. From systematic observations at a Carbon Engineering pilot plant in Canada - Carbon Engineering is a company cofounded in 2009 by David Keith, professor of applied physics at the School of Engineering and Applied Science, Harvard University - it appears that "depending on financial assumptions, energy costs, and the specific choice of inputs and outputs, the levelized cost per ton $\mathrm{CO}_{2}$ captured from the atmosphere ranges from 94 to 232 $\$ / \mathrm{t}-\mathrm{CO}_{2}$ ", capture and storage included (Keith et al., 2018, p. 1). In a recent report (National Academies, 2019), a group of experts from the National 
Academies of Sciences, Engineering and Medicine, refer to a similar range in their conclusions. It is interesting to note that the $\$ 150 / \mathrm{t}-\mathrm{CO}_{2}$ Swedish tax rate sits well inside this range, implying that it pays to avoid the tax by pumping $\mathrm{CO}_{2}$ out of the atmosphere. According to a fairly comprehensive review article (Fasihi, Efimova and Breyer, 2019), it appears that with cheap renewable energy - you can take maximum advantage of locating your plant anywhere you see fit, as $\mathrm{CO}_{2}$ concentration in the atmosphere is the same everywhere - the 2018 figures become: $\$ 85-110$ in 2030 and $\$ 40-55$ in 2050. Carbon capture will be performed in numerous relatively small units; such modularity allows for economies of scale and ongoing integration of technical improvements.

Who will pay? Capturing $\mathrm{CO}_{2}$ from ambient air is a public good, as it mitigates a public bad, climate change. Only relatively small quantities of $\mathrm{CO}_{2}$ may be sold for private uses. There is no customer for the bulk of the gas that is captured. Everybody benefits from the capture, but only philanthropists or public authorities might be motivated to contribute to the cost. Some form of public cooperation must be organized, which does not exist yet. "It may pay for us to develop carbon capture and storage as a hedge against future climate change risks" (Barrett, 2012, p. 33). Rather than waiting for severe disruptions, it would be more rational to set a Climate Apollo Program in motion right now, so as to start without delay a cumulative process of technical improvements and cost reductions characteristic of emerging technologies - think of photovoltaics or of offshore wind - in order to actually achieve what looks both necessary and possible: an affordable insurance mechanism against insuperable losses.

If voluntary finance is not easily forthcoming, compulsory finance should specifically be raised. That might be from carbon taxation or from a direct implementation of the polluter-pays-principle. Considering the extremely perilous situation we are in, Myles Allen - professor of geosystem science at Oxford University and pioneer of the studies assessing the overall limit of $\mathrm{CO}_{2}$ emissions compatible with an Earth mean temperature increase kept under $2^{\circ} \mathrm{C}$ - urges that, for every ton of $\mathrm{CO}_{2}$ emitted, one ton be captured and stored, with the emitter covering the expense (Allen, 2015).

\section{NOTES}

1. From a public good, for example, a body of knowledge or a climate condition, nobody can be excluded, and nobody's use is curtailed by anybody else's use. In such a situation, absent some form of binding cooperation, nobody feels compelled to pay for the provision of the public good.

2. "Reverse auctions provide a powerful means of price discovery. They have demonstrated their usefulness in renewable electricity generation... In a reverse auction for DAC, companies interested in developing or advancing direct air 
capture are offered an opportunity to competitively bid for projects, where the bid is expressed in terms of a $\mathrm{CO}_{2}$ price the bidder is willing to accept" (Lackner and Azarabadi, 2019).

3. According to specialists at the US Geological Survey: "The technology offers virtually unlimited capacity to permanently store $\mathrm{CO}_{2}$ via a process that takes little effort to either verify or monitor" (Krevor et al., 2009, p. 1).

\section{REFERENCES}

Allen, M. (2015), "Paris emissions cuts aren't enough - we'll have to put carbon back in the ground", The Conversation, December 12.

Barrett, S. (2012), "Climate treaties and backstop technologies", CESifo Economic Studies, 58, 31-48.

Creutzig, F., C. Breyer and J. Hilaire et al. (2019), "The mutual dependence of negative emission technologies and energy systems", Energy \& Environmental Science, 12, 1780-804.

Fasihi, M., O. Efimova and C. Breyer (2019), "Techno-economic assessment of $\mathrm{CO}_{2}$ direct air capture plants", Journal of Cleaner Production, 224, 957-80.

Keith, D., G. Holmes, D. St. Angelo and K. Heidel (2018), "A process for capturing $\mathrm{CO}_{2}$ from the atmosphere", Joule, 2, 1-22.

Kelemen, P. and J. Matter (2008), "In situ carbonation of peridotite for $\mathrm{CO}_{2}$ storage", Proceedings of the National Academy of Sciences, 105, 17295-300.

Krevor, S.C., C.R. Graves, B.S. van Gosen and A.E. McCafferty (2009), "Mapping the mineral resource base for mineral carbon-dioxide sequestration in the conterminous United States", US Geological Survey Digital Data Series, 414, 1-14.

Lackner, K. and H. Azarabadi (2019), "Buying down the cost of air capture" [unpublished paper], Center for Negative Carbon Emissions, Arizona State University.

Lackner, K., P. Grimes and H.-J. Ziock et al. (1999), "Carbon dioxide extraction from air: is it an option", in Proceedings of the 24th Annual Technical Conference on Coal Utilization and Fuel Systems, March 8-11, 1999, Clearwater Florida, pp. 885-96.

Matter, J., M. Stute and S. Snaebjörnsdottir et al. (2016), "Rapid carbon mineralization for permanent disposal of anthropogenic carbon dioxide emissions", Science, 352, 1312-14.

National Academies of Sciences, Engineering, Medicine (2019), Negative Emissions Technologies and Reliable Sequestration: A Research Agenda, Consensus Study Report, Washington, DC: National Academies Press.

Olah, G.A., G.K. Surya Prakash and A. Goeppert (2011), "Anthropogenic chemical carbon cycle for a sustainable future", Journal of the American Chemical Society, 133, 12881-98.

Sarewitz, D. and R. Nelson (2008), "Three rules for technological fixes”, Nature, 456, $871-8$. 